\title{
Pengaruh Kloroform terhadap Pelarutan Bahan Perekat yang Menempel pada Braket Keramik yang Lepas dari Gigi
}

\author{
Ken Edinata $^{1 *}$, Endah Mardiati ${ }^{2}$ \\ ${ }^{1}$ Fakultas Kedokteran Gigi, Universitas Kristen Maranatha \\ ${ }^{2}$ Departemen Orthodonti, Fakultas Kedokteran Gigi, Universitas Padjajaran \\ *email: Ken.Edinata@dent.maranatha.edu; kenedinata@gmail.com
}

\begin{abstract}
ABSTRAK
Kebutuhan braket transparan pada perawatan ortodonti semakin berkembang dengan adanya kebutuhan braket sewarna gigi, terutama wanita yang memerlukan penampilan estetik maksimal. Braket yang lepas dalam perawatan ortodonti perlu direkatkan kembali. Pembersihan landasan braket yang terlepas sehingga dapat direkatkan kembali akan mengurangi biaya yang harus dikeluarkan pasien. Melakukan daur ulang braket haruslah dapat dilakukan tanpa merubah sifat fisik dan ukuran dari braket tersebut. Pengukuran uji rekat geser menggunakan Instron Universal Testing Machine dan sisa resin menggunakan skor Adhesive Remnant Index (ARI). Terdapat perbedaan kuat rekat geser braket keramik yang dibersihkan dengan kloroform selama 20 menit, 40 menit, 60 menit dengan braket keramik yang baru, Semakin lama waktu pembersihan braket keramik dengan kloroform, sisa resin adhesif akan semakin bersih dan mempunyai kuat rekat geser yang lebih tinggi. Terdapat perbedaan sisa resin adesif antara braket keramik pasca rekat yang dibersihkan dengan kloroform yang dilepas kembali dengan braket keramik pasca rekat yang baru.
\end{abstract}

Kata Kunci : perbedaan kuat rekat geser, kloroform, kuat rekat geser, ARI, braket keramik.

\footnotetext{
ABSTRACT

The need for transparent brackets in orthodontic treatment is growing with the need for tooth-colored brackets, especially for women who require maximum aesthetic appearance. Brackets that fell off in orthodontic treatment would need to be rebonding. Cleaning the mesh of the bracket so that it can be reattached reduces costs to the patient. Recycling the bracket must be possible without changing the physical properties and size of the bracket. Measurement of the shear adhesion test used the Instron Universal Testing Machine and the residual resin used the ARI (Adhesive Remnant Index) score. There is a difference in the shear strength of a ceramic bracket that is cleaned with chloroform for 20 minutes, 40 minutes, 60 minutes with a new ceramic bracket. The longer the cleaning time of the ceramic bracket with chloroform, the cleaner the remaining adhesive resin will be and will have a higher shear strength. There is a difference in the residual adhesive resin
} 
between post adhesive ceramic brackets cleaned with chloroform removed and new rebonding ceramic brackets.

Keywords: differences in shear adhesion strength, chloroform, shear strength, ARI, ceramic bracket.

\section{Pendahuluan}

Perawatan ortodonti cekat sebelum tahun 1970 menggunakan stainless steel bands yang di semen ke semua gigi dengan braket yang di solder pada band. ${ }^{1}$ Perawatan ortodonti merupakan cara untuk memperbaiki susunan gigi dan berpengaruh pada penampilan seseorang, di mana hampir setiap pasien ortodonti merupakan pasien yang memperhatikan penampilan dirinya dengan harapan dan tujuan akhirnya untuk mendapatkan penampilan dan senyum yang indah. Penampilan selama perawatan juga tetap diperhatikan oleh pasien, dan dengan besarnya keinginan pasien tersebut sehingga penampakan logam pada braket dibuat sekecil mungkin. ${ }^{2}$

Kebutuhan braket transparan pada perawatan ortodontik semakin berkembang dengan adanya kebutuhan braket sewarna gigi pada sebagian besar perawatan ortodontik cekat yang dilakukan pada pasien dewasa, terutama wanita, yang memerlukan penampilan estetik secara maksimal. ${ }^{3}$ Dengan tingginya permintaan estetik pasien selama perawatan ortodonti, pada awal tahun 1970, braket plastik diperkenalkan sebagai pilihan yang lebih estetik dari braket logam, tetapi braket polikarbonat ini dengan cepat ditinggalkan karena mudah berubah warna karena mudah menyerap air dan dengan sifat fisiknya mudah mengalami kerusakan pada slot braketnya. Sehingga pada pertengahan tahun 1980, pertama kali braket keramik dibuat dari sapphire monocrystalline dan braket keramik polycrystalline. ${ }^{4}$ Beberapa sifat fisik braket keramik adalah mempunyai warna yang stabil, bentuk yang tetap, kekuatan perlekatan yang tinggi, membuat braket keramik jauh lebih unggul dari braket plastic. $^{5}$

Braket yang lepas dalam perawatan ortodonti sering terjadi, sehingga perlu direkatkan kembali. Pembersihan landasan braket yang terlepas sehingga dapat direkatkan kembali akan mengurangi biaya yang harus dikeluarkan pasien, daripada harus menggunakan braket yang dibeli baru. ${ }^{1}$ Braket yang lepas dapat digunakan kembali dengan cara membersihkan landasan braket dengan cara mekanis dan cara kimia. Teknik mekanis dengan mengikis sisa permukaan resin dengan menggunakan bur berkecepatan rendah, digetarkan dengan periodontal scaller, disemprot dengan sandblasting, maupun dengan teknik pemanasan. ${ }^{6}$ Teknik dengan membakar braket keramik sampai berwarna merah cerry, tetapi hal ini akan merubah bentuk, warna dan keretakan dari braket keramik itu sendiri sehingga mengurangi fungsi dan estetiknya. Ada juga dengan menggunakan cairan berupa dichloromethane, ethyl acetate, kloroform sebagai pelarut resin. ${ }^{7}$

Kloroform merupakan cairan campuran senyawa organik yang memiliki kemampuan untuk melarutkan PVC, bahan plastik, gutta-percha, dan resin. Di bidang kedokteran gigi, kloroform merupakan bahan yang cukup dikenal sebagai 
pelarut resin akrilik terutama pada bidang prostodonti maupun bidang endodontik. ${ }^{8}$ Di bidang prostodonti, salah satu penggunannya untuk memperbaiki kontur gigi tiruan resin akrilik (relining) dengan cara mengembangkan kontur permukaan dan memperluas permukaan resin akrilik gigi tiruan. ${ }^{7}$ Di bidang endodontik kloroform sangat popular digunakan sebagai cairan pelarut bahan pengisi saluran akar, yang populer misalnya gutta-perca dan resilon. Resilon merupakan sistem pengisi saluran akar berbahan dasar resin yang dikembangkan sebagai alternatif dari guttapercha, dimana Resilon lebih mudah dilarutkan oleh kloroform dibandingkan dengan gutta-perca. ${ }^{9}$ Penggunaan kloroform merupakan salah satu metode yang efektif untuk memperbaiki gigi tiruan dari resin akrilik yang patah adalah dengan menggunakan kekuatan abrasi sandblasting dan dengan aplikasi dichloromethane, ethyl acetate atau kloroform untuk rebasing dan relining pada gigi tiruan resin akrilik. ${ }^{7}$ Di bidang ortodonti kloroform hanya dilakukan di luar mulut untuk membersihkan sisa resin dari landasan braket mengingat kloroform bersifat toksik dan dapat mengiritasi jaringan. ${ }^{10}$

\section{Metode Penelitian}

Penelitian ini adalah penelitian eksperimental analitik laboratoris in vitro dengan pendekatan komparatif.

\section{Prosedur Perekatan Braket}

Permukaan bukal enam puluh gigi premolar rahang atas dibersihkan dari sisasisa bahan organik dengan pumis dan rubber cup kemudian permukaan gigi dibilas dengan semprotan air sampai bersih dan dikeringkan dengan semprotan udara.

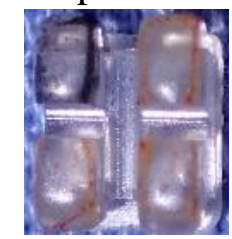

A

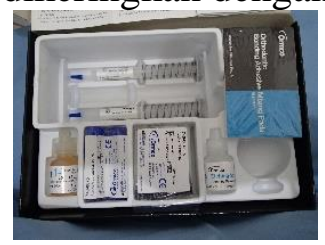

B

Gambar 1. A. Braket Keramik Ice Inspire Ormco; B. Resin Adesif System 1+ Ormco

Braket keramik direkatkan pada masing-masing gigi. Bahan perekat yang digunakan adalah satu set orthodontic bonding adhesive System 1+ dari Ormco dengan prosedur sesuai petunjuk pabrik. Sampel direndam dalam saliva buatan selama 24 jam.

\section{Prosedur Pengujian Kuat Rekat Geser}

Pengujian kuat rekat geser dengan menggunakan mesin Instron Universal Testing Instrument pada braket keramik yang baru. Cara melakukannya adalah dengan tiap spesimen diletakkan/ dijepit pada dudukan alat yang sudah disediakan pada bagian bawah pada mesin, dasar braket sejajar dengan arah gaya. Beban oklusal-gingival diaplikasikan pada braket menghasilkan gaya geser pada permukaan gigi dengan braket dan dihubungkan dengan batang pada mesin sampai braket terlepas dari permukaan gigi. ${ }^{11}$

\section{Prosedur Penilaian Skor Sisa Resin Setelah Pelepasan Braket}

Enam puluh braket keramik yang telah dilepas dari permukaan gigi diperiksa sisa resin adhesif yang menempel pada landasan dasar braket menggunakan penilaian skor sisa resin adhesif pada landasan dasar braket menggunakan skor 
Adhesive Remnant Index (ARI) yang diperkenalkan oleh Bishara dan Trulove tahun 1990, berdasarkan 5 Skor, yaitu: Skor 1 = Semua resin tertinggal pada braket, Skor $2=$ Sisa resin $>90 \%$ tertinggal pada dasar braket, Skor $3=$ Sisa resin $10 \%<\mathrm{S}$ $<90 \%$ pada dasar braket, Skor $4=$ Sisa resin $<10 \%$ pada dasar braket, Skor $5=$ Sisa resin tertinggal pada permukaan gigi.

Cara pemeriksaan sisa resin adalah sebagai berikut: dasar braket diperiksa dibawah mikroskop stereo dengan pembesar 16x dan difoto, kemudian dihitung ada berapa bagian resin yang menempel pada landasan dasar braket, penilaian sisa resin adhesif menurut skor ARI.

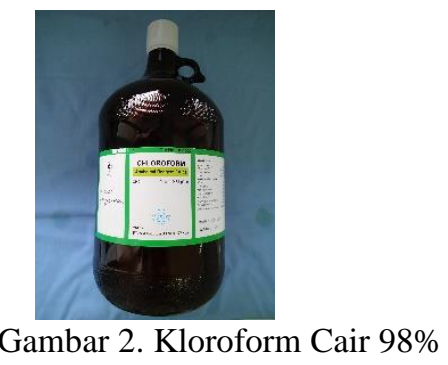

Braket dibagi menjadi tiga kelompok, yaitu 3 kelompok terdiri dari kelompok 1 (K1) adalah kelompok dimana braket dilakukan pembersihan sisa resin dengan larutan kloroform selama 20 menit lalu direkatkan kembali, kelompok 2 (K2) adalah kelompok dimana braket dibersihkan dari sisa resin dengan larutan kloroform selama 40 menit dan direkatkan kembali, dan kelompok 3 (K3) adalah kelompok dimana braket dibersihkan dari sisa resin dengan larutan kloroform selama 60 menit, pembersihan dengan kloroform dibantu digetarkan dengan amalgamator yang dimodifikasi selama satu menit setiap sepuluh menit, setelah itu landasan braket keramik dibersihkan dengan sikat lowspeed, kemudian direkatkan kembali.

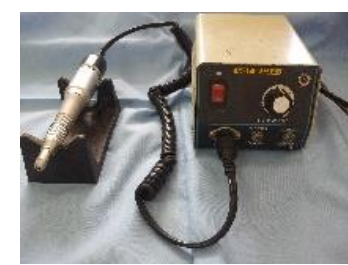

A

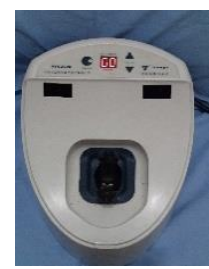

B

Gambar 3. A. Handpiece dan Mikromotor merk HNSY; B. Amalgamator

\section{Prosedur Pembersihan Sisa Resin dari Permukaan Gigi}

Permukaan bukal enam puluh gigi premolar rahang atas dibersihkan dari sisa bahan organik dan resin adhesif dengan pumis dan rubber cup kemudian permukaan gigi dibilas dengan semprotan air sampai bersih dan dikeringkan dengan semprotan udara. Perlekatan braket keramik kemudian dilakukan sama seperti prosedur awal dan direndam dalam saliva buatan selama 24 jam.

\section{Prosedur Pengujian Kuat Rekat Geser}

Pengujian kuat rekat geser dengan menggunakan mesin Instron pada braket keramik kelompok K1, K2 dan K3. Cara melakukannya adalah dengan tiap 
spesimen diletakkan/ dijepit pada dudukan alat yang sudah disediakan bagian bawah pada mesin, dimana dasar braket sejajar dengan arah gaya. Beban oklusalgingival diaplikasikan pada braket menghasilkan gaya geser pada permukaan gigi dengan braket dan dihubungkan dengan batang pada mesin, ${ }^{11}$ sehingga didapatkan hasil kuat rekat geser dari masing-masing kelompok.

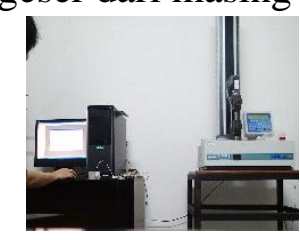

A

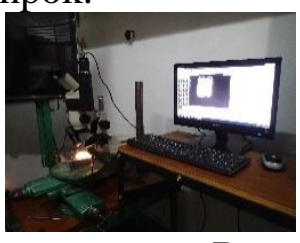

B

Gambar 4. A. Instron Universal Testing Machine; B. Kamera Mikroskop Stereo

\section{Prosedur Penilaian Skor Sisa Resin Setelah Pelepasan Braket}

Masing-masing braket keramik dari tiap kelompok dilakukan pemeriksaan sisa resin adhesif yang menempel pada landasan braket dengan mikroskop stereo dan difoto menggunakan skor $A R I$.

\section{Hasil Penelitian}

Tabel 1. Perbandingan Perbedaan Kuat Rekat Geser Braket Keramik yang Dibersihkan dengan Kloroform selama 20, 40, dan 60 Menit

\begin{tabular}{cc}
\hline Waktu & Rata-rata \\
\hline 20 menit & $5.7690 \pm 0.18247$ \\
40 menit & $5.9855 \pm 0.31164$ \\
60 menit & $7.0985 \pm 0.47142$ \\
Bracket Baru & $7.5597 \pm 0.32423$ \\
\hline
\end{tabular}

Tabel 2. Analisis Perbedaan Kuat Rekat Geser Braket Keramik yang Dibersihkan dengan Kloroform Selama 20, 40 dan 60 menit.

\begin{tabular}{ll}
\hline waktu & $p$-val \\
\hline $20^{\prime}: 40^{\prime}$ & $0.025^{*}$ \\
$20^{\prime}: 60^{\prime}$ & $0.000^{*}$ \\
$40^{\prime}: 60$ & $0.000^{*}$ \\
Baru: $60^{\prime}$ & $0.000^{*}$ \\
\hline
\end{tabular}

Ket $:$ PKRG $=$ Perbedaan Kuat Rekat Geser, Baru, 20 menit, 40 menit 60 menit, $p$-value $0.000<0.05$ sehingga bermakna, $*=$ signifikan.

Tabel 3. Hasil Skor Sisa Resin pada Braket Keramik Kontrol dengan Braket Keramik yang Dibersihkan dengan Kloroform Selama 20, 40 dan 60 Menit.

\begin{tabular}{lcccccc}
\hline $\begin{array}{l}\text { Kebalikan } \\
\text { Skor ARI }\end{array}$ & 5 & 4 & 3 & 2 & 1 & Jumlah \\
\hline Bracket Baru & 13 & 1 & 16 & 16 & 14 & 60
\end{tabular}




\begin{tabular}{lcccccc}
20 menit & 4 & 1 & 13 & 2 & 0 & 20 \\
40 menit & 1 & 2 & 11 & 6 & 0 & 20 \\
60 menit & 4 & 1 & 10 & 5 & 0 & 20 \\
jumlah & 22 & 5 & 50 & 29 & 14 & 120 \\
\hline
\end{tabular}

Ket : KSA= Kebalikan Skor ARI bracket baru, waktu 20 menit, waktu 40 menit,dan waktu 60 menit.

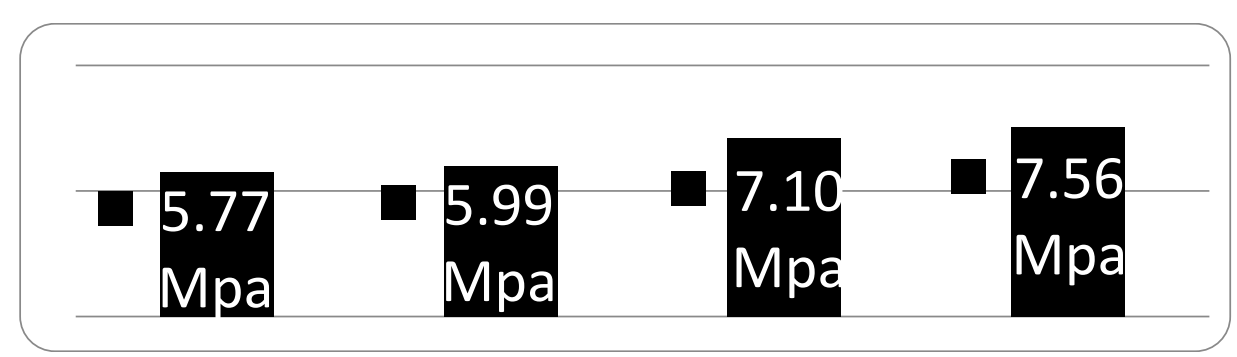

Ket : $n t l=$ waktu 20 menit, $n t 2=$ waktu 40 menit, $n t 3=$ waktu 60 menit, nb=baru.

Gambar 5. Diagram Nilai Rata-rata Kuat Rekat Geser Braket Keramik

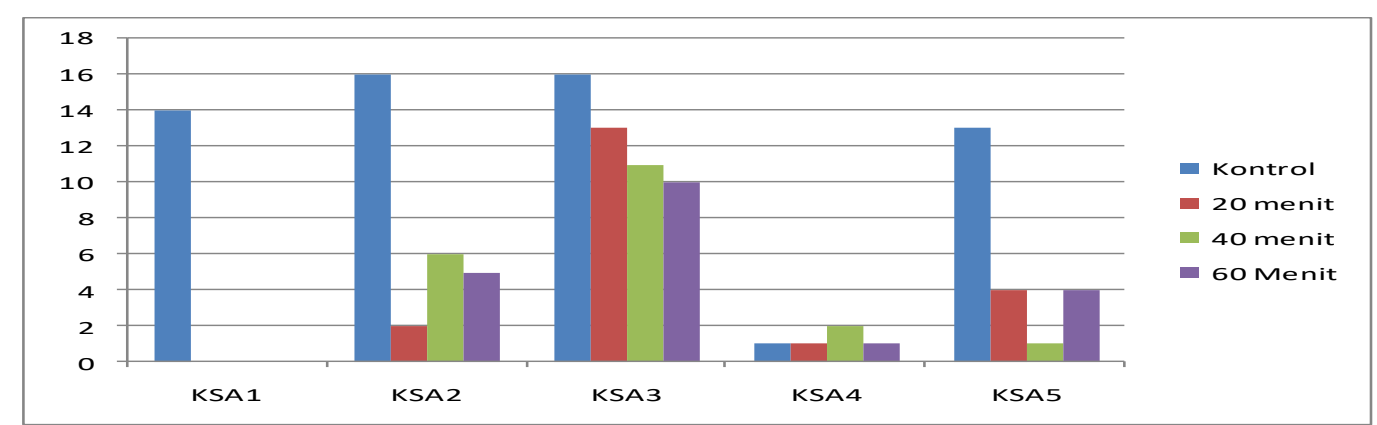

Ket $: \mathrm{KSA}=$ Kebalikan Skor ARI Biru $=$ Baru, Merah $=20$ menit, Hijau $=40$ menit, Ungu $=60$ menit.

Gambar 6. Diagram Kebalikan Skor ARI

\section{Pembahasan}

Berbagai macam cara dikembangkan untuk dapat mendaur ulang kembali braket keramik untuk tetap mempertahankan retensi mekanik pada landasannya. Melakukan daur ulang braket dapat haruslah dapat dilakukan tanpa mengubah sifat fisik dan ukuran dari braket tersebut. ${ }^{1}$

Dalam penelitian ini terdapat perbedaan kuat rekat geser braket keramik yang dibersihkan dengan kloroform selama 20 menit, 40 menit dan selama 60 menit. Kuatnya perlekatan suatu braket berhubungan erat dengan kekasaran permukaan landasan dengan permukaan gigi dan luasnya permukaan perlekatan, namun untuk braket keramik beberapa faktor lainnya yang juga turut mempengaruhi diantaranya adalah bentuk landasan braket, pemilihan bahan adesif, jenis etsa email, dan lamanya waktu etsa. Kekasaran permukaan, luas permukaan dari retensi mekanik dengan pola yang tidak teratur sangat membantu dalam perlekatan braket. ${ }^{12}$

Jumlah resin zat terlarut tergantung pada banyaknya jumlah pelarut kloroform, seiring dengan bertambahnya waktu semakin banyak terjadi interaksi dengan pelarut dan jumlah massa resin terlarut juga akan bertambah. ${ }^{10}$ Dengan membandingkan antara kontrol, 20 menit, 40 menit dan 60 menit waktu 
pembersihan dengan kloroform dengan jumlah sampel yaitu 20 sampel. Pada waktu perendaman selama 20 menit diperoleh nilai rata-rata 5.7690 Mpa dengan standar deviasi \pm 0.18247 , nilai minimal 5.48 Mpa dan nilai maksimal 6.10Mpa. Pada waktu pembersihan selama 40 menit diperoleh nilai rata-rata 5.9855 Mpa dengan standar deviasi \pm 0.31164 , nilai minimal 5.47 Mpa dan nilai maksimal 6.59 Mpa. Pada waktu pembersihan selama 60 menit diperoleh nilai rata-rata $7.5597 \mathrm{Mpa}$ dengan standar deviasi \pm 0.32423 , nilai minimal 7.05 Mpa dan nilai maksimal 8.26 Mpa. Menurut Reynolds gaya yang dapat diterima secara klinis untuk menggerakkan gigi di bidang ortodonti adalah sebesar 5,9- 7,8 Mpa. ${ }^{13}$

Besarnya jumlah resin yang terlarut akan sebanding dengan ketebalan volumenya. ${ }^{9}$ Berdasarkan hasil uji Wilcoxon diperoleh nilai untuk, 20 menit dengan 40 menit $\mathrm{p}=0.025,20$ menit dengan 60 menit $\mathrm{p}=0.000,40$ menit dengan 60 menit $\mathrm{p}=0.000$, dimana lebih kecil dari $\mathrm{p}<0.05$ sehingga dapat disimpulkan bahwa terdapat perbedaan secara bermakna antara yang dibersihkan selama 20 menit, 40 menit dan 60 menit. Analisis statistik menunjukkan perbedaan kuat rekat geser braket keramik yang dibersihkan degan kloroform selama 60 menit merupakan kuat rekat geser braket keramik pasca rekat yang memiliki kuat rekat geser tertinggi perbedaan yang bermakna $(\mathrm{p}<0,05)$, di mana seiring dengan bertambahnya waktu terjadi jumlah massa resin terlarut juga akan bertambah. ${ }^{9}$

Kloroform merupakan campuran organik yang memiliki kemampuan untuk melarutkan berbagai macam senyawa plastik. $^{8}$ Hasil penelitian menunjukkan bahwa braket keramik mengalami perubahan kuat rekat geser antara yang baru, yang dibersihkan dengan kloroform selama 20 menit, 40 menit dan 60 menit. Perbedaan kuat rekat geser braket keramik yang dibersihkan dengan kloroform selama 20 menit adalah yang terkecil dengan rata-rata sebesar 5,7690 Mpa, jika dibandingkan dengan kuat rekat geser braket keramik yang dibersihkan dengan kloroform selama 40 menit dengan rata-rata sebesar 5,9855 Mpa dan braket keramik yang dibersihkan dengan kloroform selama 60 menit memiliki kuat rekat geser tertinggi dengan rata-rata sebesar 7,0985 Mpa.

Braket keramik yang baru memiliki kuat rekat geser yang lebih tinggi dibandingkan dengan braket keramik pascarekat. ${ }^{14}$ Berdasarkan uji statistik, didapatkan perbedaan secara bermakna antara yang dibersihkan selama 60 menit dengan rata-rata 7,0985 dan standard deviasi sebesar 0,47142 dibandingkan dengan dengan braket keramik yang baru dengan rata-rata sebesar 7,5597 dan standard defiasi sebesar 0,32423 nilai $p$-value 0.000 dimana lebih kecil dari $p<0.05$ sehingga dapat disimpulkan bahwa terdapat perbedaan secara bermakna (Tabel 5). Rata-rata kuat rekat geser dari braket keramik yang telah dipakai lebih rendah jika dibandingkan dengan braket yang baru, namun masih dalam batas dapat digunakan secara klinis. ${ }^{15}$ Kuatnya perlekatan antara braket keramik dan adesif seharusnya lebih kuat dibandingkan dengan antara adhesif dan email dalem kuat rekat geser. ${ }^{16}$

Pada penelitian ini kebalikan Skor ARI 3 dengan jumlah total braket terbanyak dengan jumlah total sebanyak 50 buah, dimana lebih dari $10 \%$ dan kurang dari $90 \%$ sisa resin melekat pada dasar braket, terjadi pada 16 buah braket keramik baru, 13 buah braket pasca rekat yang dibersihkan dengan kloroform selama 20 menit, 11 buah braket pasca rekat yang dibersihkan dengan kloroform selama 40 menit, dan 10 buah braket pasca rekat yang dibersihkan dengan kloroform selama 60 menit. 
Untuk menghindari rusaknya email, lepasnya braket dari permukaan gigi seharusnya terjadi pada adesif, antara permukaan braket dengan resin daripada permukaan resin dengan email. ${ }^{13}$

Braket keramik dengan retensi landasan secara mekanik akan secara signifikan mempunyai kuat rekat geser yang lebih rendah dan fraktur email yang lebih sedikit dibandingkan braket dengan retensi secara kimia. ${ }^{5}$ Kekasaran permukaan, luas permukaan dari retensi mekanik dengan pola yang tidak teratur sangat membantu dalam perlekatan braket. ${ }^{12}$ Kebalikan Skor ARI 4 merupakan yang terkecil dengan jumlah total braket sebanyak 5 buah, dimana lebih dari $90 \%$ sisa resin melekat pada dasar braket, terjadi pada 1 buah braket keramik baru, 1 buah braket pasca rekat yang dibersihkan dengan kloroform selama 20 menit, 2 buah braket pasca rekat yang dibersihkan dengan kloroform selama 40 menit, dan 1 buah braket pasca rekat yang dibersihkan dengan kloroform selama 60 menit, disini terlihat bentuk struktur landasan braket juga sangat mempengaruhi kekuatan perlekatan braket dengan berdasarkan geometri (ketebalan, ukuran, dan distribusi) antara resin-tag dan distribusi tekanan antara resin dengan permukaan braket. ${ }^{12}$

Berdasarkan penelitian yang telah dilakukan maka didapat uji hipotesis sebagai berikut :

1. Terdapat perbedaan sisa resin antara braket pascarekat baru dengan braket pascarekat yang dibersihkan dengan kloroform.

Pendukung : Gambar 4 dan gambar 5 dan tabel 1, 2, 3.

Kesimpulan : Berdasarkan hasil pengujian tersebut, dapat disimpulkan bahwa

\section{hipotesis diterima}

2. Terdapat perbedaan kekuatan uji rekat geser braket keramik pascarekat yang dibersihkan dengan kloroform selama 20 menit, 40 menit dan selama 60 menit

Pendukung : Gambar 4 dan gambar 5 dan tabel 1, 2, 3.

Kesimpulan : Berdasarkan hasil pengujian tersebut, dapat disimpulkan bahwa

\section{hipotesis diterima}

3. Terdapat perbedaan kuat rekat geser antara braket keramik yang baru dengan braket keramik pascarekat yang dibersihkan dengan kloroform

Pendukung : Gambar 4 dan gambar 5 dan tabel 1, 2, 3.

Kesimpulan : Berdasarkan hasil pengujian tersebut, dapat disimpulkan bahwa

\section{hipotesis diterima}

\section{Simpulan}

1. Kloroform merupakan salah satu alternatif cara membersihkan braket keramik yang dapat digunakan.

2. Pada penelitian ini braket keramik pasca rekat memperoleh kuat rekat geser secara maksimal setelah dibersihkan dengan Kloroform dengan konsentrasi 98\% dengan waktu 60 menit, sehingga penerapannya secara klinis kurang efisien dari segi waktu. Terdapat perbedaan kuat rekat geser braket keramik pascarekat yang dibersihkan dengan kloroform selama 20 menit, 40 menit, 60 menit dengan braket keramik yang baru. Semakin lama waktu pembersihan braket keramik pascarekat dengan kloroform, sisa resin 
adhesif akan semakin bersih dan mempunyai kuat rekat geser yang lebih tinggi.

3. Terdapat perbedaan sisa resin adesif antara braket keramik pascarekat yang dibersihkan dengan kloroform dengan braket keramik pascarekat yang baru.

\section{DAFTAR PUSTAKA}

1. Tavares, S.W., et.al. Shear Bond Strength of New and Recycled Brackets to Enamel. Braz Dent J, 2006;1(17):44-48

2. Jena, A.K., et.al. Physical Properties and Clinical Characteristics of Ceramics Brackets : A Comprehensive Review. Trends. Biomater. Artif Organs, 2007; 2(20): 50-66

3. Karamouzos, A., et.al. Clinical Characteristics and Properties of Ceramics Bracket: A Comprehensive review. Am J. Orthod. Dentofac, Orthop, 1997;1(112): 34-40

4. Bishara, S.E., et.al. Enamel Cracks and Ceramic Bracket Failure During Debonding In Vitro. Angle Orthodontist, 2008; 6(78):1078-1083

5. Kuang Liu, J., et.al. Bond Strength and Debonding Characteristics of A New Ceramic Bracket. Am J. Orthod. Dentofac, Orthop, 2005; 6(128): 761-765

6. Sharma-Syal., et.al. The Influence of Orthodontic Bbracket Base Design on Shear Bond Strength. Am J. Orthod. Dentofac, Orthop, 2003; 1(124): 74-82

7. Shimizu Hiroshi \& Takahashi Yutaka. Review of Adhesive Techniques Used in Prosthodontic Practice. Journal of Oral Science, 2012; 3(54):205211

8. Rubino, G.A., et.al. Solvency Capacity of Gutta-Percha and Resillon Using Chloroform, Eucaliptol, Orange Oil or Xylene. J Health Sci Inst, 2012; 1(30): $22-25$

9. Khojastehpour, L., et.al. A Comparison of the Effectiveness of Chloroform in Dissolving Resilon and Gutta-Percha. Journal of Dentistry, 2011; 1(8):19-24

10. Watts, P., et.al. Chloroform, Concise International Chemical Assessment Document 58. United Nations Environtment Programme. 2004. 1-58 
11. Theodorakopoulou, L. P., et.al. Evaluation of The Debonding Characteristics of 2 Ceramic Brackets: An in vitro study. Am J. Orthod. Dentofac, Orthop, 2004; 3(125): 329-336

12. Kang, D.Y., et.al. Quantitative Analysis of Mechanically Retentive Ceramic Bracket Base Surfaces with A Three-Dimensional Imaging System. Angle Orthodontist, 2012; 0(00): 1-7

13. Bishara, S.E \& Fehr, D.E. Ceramic Brackets: Something Old, Something New, A Review. Seminars in Orthodontics, 1997; 3(3): 178-188

14. Chung, C.H., et.al. Shear Bond Strength of Rebonded Mechanically Retentive Ceramic Brackets. Am J. Orthod. Dentofac, Orthop, 2002; 3(122): 282-287

15. Toroglu, M.S \& Karan, S. Porcelain Refinishing with Two Different Polishing System after Orthodontic Debonding. Angle Orthodontist, 2008; 5(78): 947-953

16. Watts, P., et.al. Chloroform, Concise International Chemical Assessment Document 58. United Nations Environtment Programme. 2004. 1-58 